\title{
Inclusão na mídia: práticas de engajamento na contemporaneidade
}

\author{
Fernanda de Camargo Machado*
}

\section{Resumo}

Esse trabalho submete à problematização um aspecto emblemático no tempo presente: a persuasão ao engajamento social na causa inclusiva por meio da mídia. $\mathrm{O}$ estudo enreda-se a algumas possibilidades analíticas lançadas pela noção de governamentalidade, cunhada por Michel Foucault, tendo como objetivo entender como os processos de conexão dos sujeitos à verdade da inclusão vem sendo mobilizados, a partir de alguns discursos midiáticos na atualidade. Assim, esse artigo tem como meta problematizar como o engajamento à causa inclusiva produz efeitos de subjetivação a partir dos discursos midiáticos. Como material de análise, foram escolhidos dois artefatos culturais contemporâneos: uma propaganda e um evento que tratam da necessidade da inclusão e da vigilância de todos os cidadáos para que tal processo se efetive no Brasil. Ao final da investigação, foi possível destacar como efeitos de subjetivação, um conjunto de enunciados que capturam os sujeitos em três vértices: o sentido politicamente correto da inclusão, o autoaperfeiçoamento e a noção de parceria ou associação lucrativa com a diversidade.

Palavras-chave: Discurso; Inclusão; Mídia.

* Professora doutora do Instituto Federal Farroupilha, Alegrete, Rio Grande do Sul, Brasil. 


\section{Inclusion in the media: engagement practices in contemporary}

\section{Abstract}

This work questions an emblematic aspect of the present time: persuasion to social engagement and inclusion through the media. The study entangles to some analytical possibilities launched by the notion of governmentality, coined by Michel Foucault, aiming to understand how the processes of connection of the subjects to the truth of the inclusion have been mobilized, from some media discourses in the present time. Thus, this article aims to problematize how the engagement to the inclusive cause produces subjectivation effects from the media discourses. As material for analysis, it was chosen two contemporary cultural artifacts: an advertisement and an event that address the need of inclusion and surveillance of all citizens for such a process to take effect in Brazil. At the end of the research, it was possible to highlight as effects of subjectivation a set of statements that capture the subjects in three vertices: the politically correct sense of inclusion, the self-improvement and the notion of a lucrative partnership or association with diversity.

Keywords: Discourse; Inclusion; Media.

\section{Sinalizações iniciais}

Esta pesquisa emerge a partir da circulação de uma série de anúncios em diferentes âmbitos publicitários que tratam do tema da inclusão social das pessoas com deficiência no nosso país. A promoção e divulgação de eventos, mensagens e propagandas vem ocupando um espaço cada vez mais amplo nos diversos veículos de comunicação em massa. Por inclusão, entende-se muito mais do que um paradigma educacional ou social; toma-se inclusão como um princípio de organização da sociedade, propulsionado pela lógica neoliberal, postura essa assumida por autores, como Thoma \& Hillesheim (2011) e Lopes \& Hattge (2009). Nesse sentido, traz-se para o centro do debate a racionalidade que coloca em movimento os discursos da inclusão, com o propósito de compreender sua mecânica e discutir seus efeitos de verdade.

Assim, dois artefatos culturais chamaram a atenção e constituem-se no foco analítico deste estudo: um anúncio televisivo e um evento urbano (uma espécie de parade), os quais serão descritos mais adiante. É importante salientar que não interessa aqui avaliar ou analisar somente o papel das mídias ao constituir um palco para a inclusão. $\mathrm{O}$ objetivo desse trabalho é submeter à problematização um aspecto emblemático no tempo presente: a persuasão ao engajamento social na causa inclusiva; as idas e vindas do cenário montado para criar estas formas de engajamento; as técnicas empreendidas para tal e seus efeitos na produção de modelos de conduta frente às pessoas com deficiência.

Diante disso, esse trabalho tem como objetivo analisar algumas produçóes midiáticas sobre a inclusão, de forma a compreendê-las como discursos em operação, 
entendendo as possíveis relações entre inclusão, mídia e subjetivação na atualidade. Assim, esse artigo tem como meta problematizar o engajamento na causa inclusiva como efeito de subjetivação pelos discursos midiáticos, a partir do instrumento conceitual "governamentalidade", de Michel Foucault - questôes que serão discutidas no tópico que segue.

\section{Postura teórica e metodológica}

Esse estudo enreda-se a algumas possibilidades analíticas lançadas pelos Estudos Foucaultianos, em particular, pelos Estudos da Governamentalidade. Em Foucault, a junção aperfeiçoada de formas de condução dos homens, a qual mira todos e cada um dos indivíduos, criando e sintonizando seus desejos às convençôes estatais e de mercado, resultou na "governamentalização do Estado", cenário montado a partir do Século XVI. Em outras palavras, Foucault (2006) propôe outro entendimento sobre as relaçôes entre Estado, Sujeito, Sociedade e Mercado, ao criar a ferramenta analítica "governamentalidade". Para ele, o processo de otimização do poder, pela economia política, que implica em estratégias que tem como efeito o máximo controle pelo mínimo investimento de poder, seria uma tendência, uma racionalidade específica. Nessa lógica, produzir condutas que relacionam o sujeito com os demais - por meio de procedimentos que visam gerir a população - aliadas a práticas que o sujeito empreende com ele mesmo - pela ética - além da amenizaçáo do risco, permite a autogestáo da sociedade. Mas, para que essa lógica seja eficiente, algumas táticas e técnicas precisam ser inventadas/acionadas.

É nesse regime que a inclusão, como elemento de participação e acesso de todos, toma inteligibilidade. Não basta ser parte da sociedade, é preciso participar. Mais do que isso, é preciso querer participar de certos espaços e incentivar que todos participem.

O foco deste trabalho está no entendimento dos meandros que produzem o engajamento à inclusáo como atitude interessante na lógica contemporânea, nas formas de subjetivação empregadas e nas ressonâncias desse processo numa sociedade que se pretende cada vez mais inclusiva.

Como material de análise, escolheu-se dois artefatos contemporâneos: uma propaganda e um evento urbano. A propaganda escolhida fora veiculada durante curto espaço de tempo e alguns canais de televisão aberta. Antes de realizar uma análise dos aspectos técnicos do anúncio, o que se pretende é lançar um olhar que problematize sua mensagem, a saber: "Inclusão social: você já nasce com esse pensamento, não perca isso ao longo da vida!”.

Nesse sentido, convém mencionar que, com Silva (1999), tomo a publicidade não só como elemento que pode auxiliar no trabalho pedagógico, mas como uma pedagogia, um conjunto sistemático de significados que criam, por meio da linguagem, representaçóes do mundo. A publicidade ensina, por exemplo, como se comportar diante de determinada situaçáo. Mais do que analisar a propaganda como prática discursiva, temos o intuito de relacioná-la o terreno epistemológico, o solo que possibilita falar, nesse momento histórico, dessa maneira. Por isso, mais uma vez, 
que esse artigo tem como foco os discursos produzidos e produtores da mensagem publicitária e náo a propaganda em si. De acordo com Silva (1999, p.15), é preciso "compreender [...] como funciona essa nova economia do afeto e do sentimento, na qual a apropriada utilização da mídia adquire um papel central".

Outro artefato do nosso tempo que trago à problematização é evento no âmbito do Prêmio Empreendedorismo Social: a Virada Inclusiva.

\section{Virada Inclusiva terá mais de 500 atraçóes no Estado de São Paulo}

No próximo final de semana (dias 3 e 4), acontece a 2a Virada Inclusiva de São Paulo. O evento é uma série de entretenimentos nas áreas de cultura, lazer e esporte voltados para que as pessoas com e sem deficiência participem juntas. Serẫo cerca de 500 atraçóes espalhadas em diversos pontos da capital e em cidades do interior. [...] No sábado (3), também é comemorado o Dia Internacional da Pessoa Com Deficiência (Acesso em 01.12.2011).

Ao visualizar a reportagem sobre o evento, é possível problematizar um aspecto emblemático no tempo presente: a "espetaculização" da diversidade - sua produção e seu consumo simbólico a partir da linguagem midiática. Nesse registro, as questôes que interessam a essa pesquisa são: Como a inclusão social vem sendo produzida e consumida pela mídia? Que efeitos de subjetivação produzem?

A inscrição do estudo se dá numa perspectiva de análise que não busca pelo oculto, mas por aquilo que está na superfície discursiva, como diria Foucault (2006). Nesse sentido, não há uma interpretação ou desvelamento de significados "escondidos pela névoa de uma ideologia”. O empreendimento analítico que se aproxima dessa forma de olhar desapegada da verdade, tenta tomar seus objetos e sujeitos como constituídos e constituidores de discursos. Em outras palavras, não importa se algo é ou não verdadeiro, se existem uma ou muitas verdades, mas de entender as correlações de forças implicadas na produção histórica da verdade.

Said (2010) demonstra essa postura metodológica ao problematizar a produção do Oriente pelas representaçôes do Ocidente. Em outras palavras, a forma como cultura usa a linguagem para criar significados. $\mathrm{O}$ status de verdade assumido por esses significados depende dos engendramentos e das posiçóes de quem narra e de quem é narrado, ou seja, das relaçôes de poder e saber. Por esse motivo, Said e os demais pesquisadores que atrelam suas análises a essa perspectiva investigativa, não estão interessados no que é mesmo verdade, mas sim nas condiçôes que colocam as verdades nessa posição.

$\mathrm{Na}$ conjuntura desses estudos, a história não toma lugar de origem ou sucessão linear de fatos. A história, num sentido genealógico, que Foucault toma emprestado de Nietzsche, refere-se muito mais ao solo de onde emergem os conjuntos de enunciados, sempre dispersos e fluidos. Problematizar o presente a partir dos seus pontos de apoio históricos constitui-se, por assim dizer, num "método", numa forma de compreender o que muda e o que persiste do passado na contemporaneidade. Esta é a principal questão que move Foucault: como nos tornamos o que somos na atualidade. 
Já diz Said (2010) que "os dados a serem observados são o estilo, as figuras de retórica, o cenário, os esquemas narrativos, as circunstâncias históricas e sociais, e não a correção da representação, nem sua fidelidade a alguma grande original” (p. 51). Nessa esteira, não há preocupação com valoração de discursos, mas no entendimento de seus cruzamentos, aproximaçôes, distanciamentos, isto é, as condiçóes de possibilidades, aquelas circunstâncias e conveniências históricas que permitem ou criam a necessidade de falar de algo de um determinado jeito, atribuindo-lhe sentido, classificação, posicionamento.

\section{Eu me incluo, você se inclui, todos se incluem...}

Antes de promover um debate sobre a materialidade e suas implicaçóes, considero oportuno realizar uma breve "volta da página", apontando as condiçóes de possibilidades do nascimento dos discursos da inclusão. Entendemos a inclusão, enquanto incentivo à participaçáo e acesso de todos a determinados espaços sociais, como uma grande rede que se tece em torno de políticas e práticas conectadas aos interesses e conveniências do modo de vida neoliberal.

Por neoliberalismo, com Foucault, compreende-se a lógica que vem se empreendendo desde a década de 1970, em que o mercado assume posição central na criaçáo de significados. Com isso, o papel do Estado se reconfigura, incentivando a autocondução. Assim, se neoliberalismo clássico, o Estado gerenciava o mercado, no neoliberalismo, a relação inverte-se. O mercado cria e monitora o funcionamento do Estado e das suas relaçóes com os sujeitos e destes com eles próprios, pois isso torna o processo mais produtivo e econômico (GADELHA, 2009).

É mais eficaz que cada sujeito passe a gerir seu ingresso e permanência nos espaços sociais estabelecidos para tal (escola, universidade, mercado de trabalho, espaços de consumo, etc). Isso diminui o risco de que ele se torne um "peso", alguém que não produz e não consome, ou ainda que passe a utilizar de meios ilícitos para efetuar essas açóes. Nesse contexto, é possível visualizar uma série de medidas inclusivas, com vistas à criação do desejo de inserção de todos em diferentes âmbitos. Como exemplos, pode-se citar, entre vários outros, a implementação do REUNI (Programa de Apoio a Planos de Reestruturação e Expansão das Universidades Federais) e do PROUNI (Programa Universidade para Todos).

Ademais, "pertencer", atravessar uma suposta fronteira da exclusáo, não garante atingir esse objetivo de prevençâo do risco por meio da inclusão. É necessário que, além de empreender o esforço de buscar sua própria inclusão, cada um de nós, permaneça como que num estado permanente de busca por se manter incluído. Para tanto, programas de acompanhamento desse processo são acionados na tentativa de prever e subtrair o risco iminente de evasão.

Dito de outra forma, a necessidade de controle social de "todos e de cada um" vai criando as condiçóes de possibilidades para a implementação de políticas de inclusáo como um imperativo neoliberal, no final do século XX, o que atende a uma demanda específica, de aproximar para governar melhor. Desse lugar, governar melhor não significa governar mais, senão utilizar a frugalidade do poder a serviço da 
máxima eficácia da condução das condutas. No sentido de aperfeiçoar essas estratégias, a racionalidade contemporânea vem agregando e enfocando o controle aos seus esforços de vigilância (VEIGA-NETO, 2008). Não se trata de uma permuta total de uma por outra, mas de uma incorporaçáo ou, talvez, um refinamento das estratégias de governamento.

\section{Holofotes na diversidade e engajamento inclusivo: a produção do politicamente correto, do autoaperfeiçoamento e da parceria com o outro}

No cenário contemporâneo descrito anteriormente, no qual todos são "soldados" da própria inclusão, torna-se interessante que cada um se preocupe também com a inclusão dos outros. Dessa maneira, empreender técnicas que ensinem a cuidar de $\mathrm{si}^{1}$ e dos outros, sob determinada forma, parece ser extremamente conveniente aos objetivos políticos.

Ao visualizar o anúncio e a reportagem sobre o evento, uma questão destacouse: a persuasão ao engajamento na causa inclusiva, a partir da "espetaculização" da diversidade - sua produção e seu consumo simbólico a partir da linguagem midiática, disposta ao grande público, que é a população. A visibilidade da inclusão como "bandeira dos bons" é uma estratégia típica do nosso tempo, o qual utiliza o marketing e a publicidade como partes de uma engrenagem de subjetivação, proliferação e consumo de verdades.

Aqui, com Canclini (2005), entende-se consumo muito menos no sentido financeiro e muito mais no sentido simbólico. A captura e o uso dos outros e de si, enquanto processo negociado e conveniente de produção de subjetividades no circuito cultural, denotam a essa constante busca por aprimoramento, pela ocupação de espaços, pela mobilidade identitária. Entender-me, enquanto sujeito de uma causa, indica meu lugar no mundo, minhas opiniôes, meu grupo, minhas adesôes, meu papel social. Toma-se "subjetividade" como as possibilidades de constituição da experiência de si, "[n] a correlação, numa cultura, entre campos de saber, tipos de normatividade e formas de subjetividade" (FOUCAULT, 2007, p. 10).

O que a análise dos dados permitiu discutir é a persuasão de cada sujeito a tornar-se um vigilante da causa inclusiva, como uma premissa politicamente correta. Nesse sentido, problematiza-se a produção do engajamento a partir da implementação de técnicas de si, ou seja, de mecanismos de convencimento dos sujeitos a se conduzir por uma verdade (Foucault, 2004). Na esteira dessa teorização, é possível entender como o autogovernamento torna-se interessante no funcionamento de uma economia política, que conecta "as técnicas de dominação exercidas sobre os outros e as técnicas de si” (FOUCAULT apud VEIGA-NETO, 2005, p. 25).

Nessa linha, todos e cada um assumem a função de serem pastores e soberanos de si mesmos. É nessa medida que a governamentalidade se fortalece, produzindo sujeitos na intersecção da política com a ética, já que é da sintonia da autonomia com os fins políticos que se torna possível produzir e nutrir um Estado de governo. Nesses termos, todos e cada um, indivíduo e população, são direcionados e, principalmente, 
autodirecionados, de forma a contribuir com o grande projeto de cidadania (neo) liberal, que tem na ordem social sua matriz, promessa e busca constante.

Aí se pode compreender a constituição do palco para o exercício de convencimento do papel de todos e de cada um na construçáo de uma naçáo mais feliz. Foucault nos mostra que a liberdade e o poder - entendido como um investimento consentido numa relação de "lucro" compartilhado - são conexos, a partir, principalmente, do Estado de razão liberal. Essa premissa se mantém e se intensifica no regime governamental neoliberal; cada cidadáo é convidado a se engajar e exercer o poder sobre si mesmo, investindo e gerenciando a sua própria posição de inclusão. A busca por manter-se incluído é produzida estrategicamente como uma escolha pessoal do sujeito. Assim, a dinâmica social tem condiçóes de se tornar uma maquinaria autogovernada e, por conseguinte, mais eficaz.

A frase "Inclusão social: você já nasce com esse pensamento, não perca isso ao longo da vida!" é um exemplo de como a propaganda busca convencer a todos a realizar uma "volta a um estado natural inclusivo", um retorno a um suposto "verdadeiro eu”, em que cada sujeito constitui-se na relaçáo consigo mesmo, na busca pelo aperfeiçoamento pessoal e social.

Nesse registro, ao buscar elementos para uma compreensão da forma como nos tornamos o que somos na atualidade, é possível fazer um ensaio genealógico, citando alguns rupturas e continuidades na constituição histórica das verdades. Uma delas parece ser a naturalização das atitudes inclusivas como uma espécie de retomada do Iluminismo na noção da "criança de Rousseau, o bom selvagem".

\begin{abstract}
Nascemos sensíveis e desde nosso nascimento somos molestados de diversas maneiras pelos objetos que nos cercam. Mal tomamos por assim dizer consciência de nossas sensações e já nos dispomos a procurar os objetos que as produzem ou a deles fugir, primeiramente segundo nos sejam elas agradáveis ou desagradáveis, depois segundo a conveniência ou a inconveniência que encontramos entre esses objetos e nós, e, finalmente, segundo os juízos que fazemos deles em relação à idéia de felicidade ou de perfeiçáo que a razão nos fornece. Essas disposiçóes se estendem e se afirmam na medida em que nos tornamos mais sensíveis e mais esclarecidos; mas, constrangidas por nossos hábitos, elas se alteram mais ou menos sob a influência de nossas opiniōes. Antes dessa alteração, elas são aquilo a que chamo em nós a natureza (ROUSSEAU apud GADOTTI, 2004, p. 94-95).
\end{abstract}

Em especial, a forma como a linguagem midiática da publicidade vem produzindo o consumo de formas específicas de compreender a inclusão, cria formas de subjetivação que abrangem um número acentuado de pessoas nas atuais circunstâncias de uso de internet, televisão e, também de ocupação dos espaços públicos, como é o caso da Virada Inclusiva.

Como diz a própria manchete, "Esse evento é uma série de práticas de entretenimento nas áreas de cultura, lazer e esporte, voltados para que as pessoas com e sem deficiência participem juntas", de forma a incentivar o convívio entre todos. 
Parece se tratar de uma estratégia reeditada e aperfeiçoada dos cânones liberais de Liberdade, Igualdade e Fraternidade, o famoso tripé da Revolução Francesa. Se a liberdade pautada nas plataformas liberais é condição para o exercício das práticas de governamento, entende-se que cabe problematizar a busca pela igualdade e a noção de fraternidade nesse "novo" jogo neoliberal. A fraternidade torna-se uma justificativa natural e espontânea para a igualdade, e esta seria condiçáo imprescindível para aquela. O sujeito com deficiência é meu parceiro na empreitada de autoaperfeiçoamento.

Dessa forma, parece fazer mais sentido deixar a diferença viver, mais que isso, conviver. Dito de outra forma, aproximá-la, torná-la produtiva para o bem de todos e de cada um, dos "com" e dos "sem" deficiência. No entanto, para que todos convivam harmonicamente em todos os espaços, é preciso o consentimento, o entendimento, a aceitação, o respeito, a tolerância, enfim, o engajamento aos discursos politicamente corretos da inclusão.

Assim, percebe-se a aliança com o incentivo ao aperfeiçoamento constante como um modo de subjetivação: tornar-se um agente atuante da inclusão como uma forma de melhorar o mundo e, principalmente, a si mesmo. No que se refere aos processos de subjetivaçáo implementados nessa esteira, pode-se apontar interessantes discussôes que denotam à capitalização da vida humana como um todo. Para ser mais específica, trata-se do Capital Humano - expressão utilizada por estudiosos da Escola de Chicago, como Shultz, a partir da metade do século XX. Desse lugar, estudos recentes - destaco, no nosso país, os de Sylvio Gadelha (2009) - vem reportando ao que parece ser outro gradiente da cultura contemporânea, em que cada um mira a si mesmo como passível de investimento e aperfeiçoamento, dando acento especial aos seus comportamentos e às suas habilidades cognitivas.

Já refere Foucault, no curso O Nascimento da Biopolítica, que o indivíduo passa a ser "empresário de si mesmo, sendo ele próprio seu capital, sendo para si mesmo seu produtor, sendo para si mesmo a fonte de [sua] renda" (2008, p. 311). Essas problematizaçóes imprimem um contundente questionamento sobre as formas de experenciar e conduzir a existência contemporânea. Nossas vontades, escolhas e apostas individuais, em todos os âmbitos, inclusive educacionais, produzem-se na sintonia com as demandas da flexibilidade e da concorrência, princípios próprios do neoliberalismo.

Assim, é possível discutir a implementação de um novo regime existencial conveniente à racionalidade em curso, uma espécie de ascética (não é por acaso que o nome da parade é "Virada"), que cria processos de subjetivação, modos de vida específicos, na ordem da flexibilidade. Costa refere que

determinados valores econômicos, à medida que migraram da economia para outros domínios da vida social, disseminando-se socialmente, ganharam um forte poder normativo, instituindo processos e políticas de subjetivação que vêm transformando sujeitos de direitos em indivíduos-microempresas - empreendedores (2009, p. 172). 
Mais uma vez, reitera-se que problematizar os movimentos dos discursos da inclusão e suas técnicas de persuasão não é ser a favor ou contra, mas compreender o cenário que é montado para colocar tal roteiro no palco, como tal engrenagem funciona e como vem produzindo posiçôes de sujeito no cenário contemporâneo.

\section{Considerações finais}

Essa pesquisa teve como meta analisar dois artefatos culturais midiáticos, tomados como discursos sobre a inclusão. Ao examinar esses artefatos, enquanto instrumentos que produzem modelos de conduta e engajamento à causa inclusiva, a partir da operação da ferramenta governamentalidade, foi possível destacar como efeitos de subjetivaçáo, um conjunto de enunciados que capturam os sujeitos em três vértices. São eles:

- O vértice do "politicamente correto" e do engajamento moral: seria recomendável tornar-se um sujeito parceiro da inclusão na medida em que a aceitação do outro é necessária para tornar aperfeiçoar a posição "cidadâ" dos sujeitos a incluir. Em outras palavras, cada sujeito é responsabilizado por suas atitudes, convidado a engajar-se nessa causa que se intitula tâo nobre. Nessa perspectiva, constituir nas relaçôes inclusivas uma matriz de conduta é indispensável para a própria manutenção da inclusão e de suas promessas de harmonia e ordem social;

- $\mathrm{O}$ vértice do autoaperfeiçoamento: cria-se um regime persuasivo para que o sujeito desenvolva e mantenha atitudes inclusivas como uma nova competência moral a ser perseguida, para tornar-se melhor;

- O vértice da parceria ou associação lucrativa: há uma promessa de ganho ao tornar-se "sócio" dos sujeitos a tolerar, aprendendo com eles nessa convivência, implicada em investimentos mútuos, em que ambos podem faturar.

É nesse contexto que se problematizou o engajamento à causa inclusiva, como prática de governamentalidade neoliberal empreendida como uma escolha politicamente correta e disponível para todos e cada um dos sujeitos, a partir da análise dos artefatos midiáticos analisados. Afinal, se ninguém pode escapar do campo de gravitação tomado como ideal, não basta que cada um se inclua, é preciso cada um se convença dos benefícios de manter todos os demais também incluídos, seja pelo autoaperfeiçoamento, seja pela associação lucrativa advinda da convivência com pessoas com deficiência.

Uma das molas propulsoras desse processo de subjetivação, no sentido de divulgação, circulação e consumo dessas práticas, é atualmente a publicidade, em seus diferentes campos de atuação (televisão, internet, rádio, outdoors...). Consumir as vantagens da inclusão faz com que ela se torne um objeto de valor, ou melhor, que torne o sujeito em estado de inclusão, alguém cujo capital humano é mais valorizado. Um dos aspectos que parecem valorizar ainda mais a performance inclusiva é, portanto, que cada um assuma essa causa, que cada um adira à essa verdade, tornando-se um "parceiro/sócio" na vigilância pela inclusão de todos. 


\section{Referências}

CANCLINI, N. G. Consumidores e Cidadáos. 5. ed. Rio de Janeiro: Editora UFRJ, 2005.

COSTA, S. S. G.Governamentalidade Neoliberal, Teoria do Capital Humano e Empreendedorismo. Educaçáo \& Realidade. Porto Alegre, v. 34, n. 2, mai/ago, p. 171-186, 2009.

FOUCAULT, M. A Hermenêutica do Sujeito. São Paulo: M. Fontes. 2004.

FOUCAULT, M. Microfísica do poder. Organização, tradução e revisão: Roberto Machado. Rio de Janeiro: Graal, 2006.

FOUCAULT, M. História da sexualidade II: o uso dos prazeres. 12. Ed. Rio de Janeiro: Ediçōes Graal, 2007.

FOUCAULT, M. Nascimento da biopolítica (1978-1979). São Paulo: M. Fontes, 2008.

GADELHA, S. Biopolítica, governamentalidade e educação: introduçấo e conexôes, a partir de Michel Foucault. Belo Horizonte: Autêntica, 2009.

GADOTTI, M. História das Idéias Pedagógicas. 8. ed. São Paulo: Ática, 2004.

LOPES, M. C.; HATTGE, M. D. (Orgs.). Inclusão Escolar: conjunto de práticas que governam. Belo Horizonte: Autêntica, 2009.

SAID, E. W. Orientalismo: oriente como invenção do ocidente. Editora Schwarcz: São Paulo, 2010.

SILVA, T. T. da. A "nova" direita e as transformaçóes na pedagogia da política e na política da pedagogia. In: GENTILI, P. A. A.; SILVA, T. T. (Org.). Neoliberalismo, qualidade total e educaçáo: visōes críticas. 7. ed. Petrópolis: Vozes, 1999, p. 9-29.

THOMA, A. S.; HILlESHEIM, B. (Orgs.). Políticas de inclusão: gerenciando riscos e governando as diferenças. Santa Cruz do Sul: EDUNISC, 2011.

VEIGA-NETO, A. Foucault \& a Educaçăo. 2. ed. Belo Horizonte: Autêntica, 2005.

VEIGA-NETO, A. Crise da modernidade e inovaçôes curriculares: da disciplina para o controle. In: Encontro nacional de didática e prática de ensino: trajetórias e processos de ensinar e aprender: lugares, memórias e culturas, 14, 2008, Porto Alegre. Anais... Porto Alegre: Edipucrs, 2008. p. 35-58. 1 CD- ROOM.

\section{Notas}

${ }^{1}$ Importante pontuar que o cuidado de si, na lógica neoliberal, năo diz respeito a uma busca por uma ética pessoal, tal como no sentido grego antigo. Parece se tratar de um "cuidar-se do outro", que atualiza o panóptico.

\section{Correspondência}

Fernanda de Camargo Machado - Instituto Federal Farroupilha, Campus Alegrete. RS-377, Km 27, Passo Novo. CEP: 97555000. Alegrete, Rio Grande do Sul, Brasil.

E-mail: nandadecm@yahoo.com.br

Recebido em 09 de agosto de 2016

Aprovado em 22 de dezembro de 2016 